\title{
Potential for Increased Epilepsy Awareness: Impact of Health Education Program in School on Teachers and Children
}

\author{
Meena Kolar Sridara Murthy ${ }^{1} \quad$ Prakashi Rajaram $^{2}$ Kannappa Shetty Mudiyanuru ${ }^{3}$ Marimuthu P. ${ }^{4}$ \\ Lakshmana Govindappa ${ }^{5}$ Madhuporna Dasgupta ${ }^{6}$
}

${ }^{1}$ Department of Mental Health Education, National Institute of Mental Health and Neurosciences, Bangalore, India

2Department of Psychiatric Social Work, National Institute of Mental Health and Neurosciences, Bangalore, India

${ }^{3}$ Psychiatric Social Work Consultant, Abhaya Hospital, Bangalore, India

${ }^{4}$ Department of Biostatistics, National Institute of Mental Health and Neurosciences, Bangalore, India

${ }^{5}$ Department of Social Work, School of Social and Behavioral Sciences, Central University of Karnataka, Gulbarga, India

${ }^{6}$ Department of Mental Health Education, National Institute of Mental Health and Neurosciences, Bangalore, India

\begin{abstract}
Address for correspondence Meena Kolar Sridara Murthy, PhD, Dr. M.V. Govindaswamy Centre, Ground Floor, Department of Mental Health Education, National Institute of Mental Health and Neurosciences, Hosur Road, Bangalore 560029, India (e-mail: meenaksiyer@gmail.com).
\end{abstract}

\section{Abstract}

Keywords

- epilepsy awareness

- health education

- awareness among teachers

- awareness among children

- school intervention
Background Although epilepsy is a common disorder, it is highly stigmatized. Not only public but even teachers are not free from stigmatization and cultural barriers. Under this condition, children with epilepsy are more vulnerable for stigmatization, social isolation, lack of support, and psychological and emotional problems. At the same time, there is an immediate need of literature focusing on intervention studies to change the attitudes of school teachers and children.

Materials and Methods The study was conducted with the objectives to evaluate knowledge, attitude, and practices about epilepsy among school teachers and children; provide educational training program to teachers; and check the efficacy of training program imparted by teacher and trainer.

Results Repeated measure of analysis of variance shows that knowledge $(F=1134.875$, $p<0.001)$, attitude $(F=2429.909, p<0.001)$, and practice $(F=2205.122, p<0.001)$ are significantly different between pre- and posttest indicated by Pillai's trace test. Similarly, from the Pillai's test knowledge $(F=49.317, p<0.001)$, attitude $(F=125.304$, $p<0.001)$ and practice $(F=178.697, p<0.001)$ are significantly different among the teachers, trainer imparted training group of children, and teachers imparted training group of children groups. It is seen that knowledge, attitude, and practice scores significantly differ between two time points and across three groups. Among all the groups, teachers imparted training group children had high level of practice.

Conclusion Inclusion of health education programs in the textbooks and health education schemes for teachers and school children is a crucial way to bring a change in their attitude, behavior, and practices.
DOI https://doi.org/

$10.1055 / \mathrm{s}-0039-3399473$

ISSN 0976-3147.
(C)2019 Association for Helping Neurosurgical Sick People
License terms

() (1) $\Theta \circledast$ 


\section{Introduction}

Epilepsy is a standout among widely recognized neurological problems that happen because of the disarrangement in the course of action of the nervous system. This happens because of the overabundance and cluttered release from the neurons in the brain resulting in the unsettling influence on sensation, leading to loss of responsiveness. ${ }^{1,2}$ Epilepsy affects around 70 million individuals all over the globe. ${ }^{3}$ Speaking from the Indian context, epilepsy is the second leading problem affecting the rural and urban population, which has made the disorder a public health issue despite being clinically benign in most cases. ${ }^{4}$

Diagnosis of epilepsy leads to a considerable amount of negative psychological effect especially on school going children as they have to face a lot of discrimination in school environment from their teachers and peers. Developing countries are somewhat lagging behind in clearing the misconceptions about epilepsy that makes it all the more challenging to live with the disorder more than the disorder itself. ${ }^{5}$ A survey of school teachers done in a developing country like Northwest Nigeria showed that there existed a considerable low level of knowledge and misconceptions related to epilepsy. ${ }^{6}$ Studies have revealed that a considerable proportion of students and teachers have misconceptions and stigma related to epilepsy that makes a child with epilepsy difficult to get in with the society. ${ }^{7}$ A study in South India showed that although $88 \%$ of people had heard about epilepsy, lack of proper knowledge has created negative attitude toward the disorder; $23 \%$ thought that it is hereditary and $23 \%$ thought it to be a type of lunacy. ${ }^{8}$ Due to the lack of proper knowledge, it has been noted that few people do not really know what to do when a person is having an episode of seizure. This facilitates the feeling of impotence that strengthens the belief that epilepsy cannot be treated. ${ }^{9,10}$

Health educational programs in developed and developing countries have resulted in increased epilepsy knowledge, adherence to treatment methods and drugs, and increased self-esteem among persons with epilepsy. ${ }^{11,12}$ In any way, it is seen that in developing countries one of the problems that is faced when it comes to communicable diseases is that epilepsy treatment gap in developing countries cannot be reduced by just providing drugs. This shows that the existing framework of the health systems is not adequate. An evaluative study of the impact of comprehensive education program on epilepsy was conducted in Chandigarh, India for school teachers. When a comparison was made on the knowledge, skills, and attitude about the first-aid management of epilepsy before and after the program, it showed improvements significantly in different categories. ${ }^{13}$

In recent times, there exists a dearth in the literature about school interventions that could bring a change among school-going children about the concept of epilepsy. ${ }^{7}$ The same holds true for the school teachers too. This is proved by a study done in Riyad, that there requires an improvement in the knowledge about epilepsy among teachers in primary school. ${ }^{14}$ The first step toward planning of an intervention is knowing the attitude of the community and stakeholders toward any disease prior to education. Health education is crucial component of disease control and can be used as an effective tool for mass communication to eradicate myths and misconceptions. Awareness among teachers and children with regard to epilepsy is the need of the hour. With this objective, the present study aims to educate the school teachers and students about epilepsy after evaluating their knowledge, attitude, beliefs, and practices so that a safer environment can be built for children with epilepsy, free from social stigma and misconceptions.

\section{Materials and Methods}

The aim of the study was to assess the efficacy of the intervention of a health education program for school teachers and children and test the efficacy of trainers of training (TOT) program aimed to create awareness among children in school by different groups. The main objectives of this study are to assess knowledge, attitude, and practices (KAP) with regard to epilepsy among teachers and children; impart the training to teachers; and check the efficacy of training program imparted by teacher and trainer.

\section{Ethics}

The research study was approved by the ethics committee of the institute. Informed consent in writing from teachers and assent from school children were taken.

\section{Study Design}

\section{Selection and Description of Participants}

It was performed among government school teachers and students in Bangalore District, Karnataka State, India. The researcher approached Education Department, Government of Karnataka, India to obtain the permission to conduct the study. After the permission, headmasters were requested to depute the interested teachers for the training program. After the permission, teachers were requested to be a part of a 2-day training program on epilepsy and total 39 teachers from eight schools participated in this program. Once the training was provided to teachers, the teachers were requested to conduct the program in their school. Out of 39 teachers trained by clinician, only 5 teachers conducted the training among 50 children and returned the filled questionnaires. Other teachers could not conduct the intervention because of academic pressure, their transfer to other places, and they not feeling comfortable.

Again, to match the number of children, the researcher conducted a study among 50 children. The closest government school was chosen and permit to carry out the intervention research was acquired by the school principal and Education Department, Government of Karnataka, India.

The researcher imparted health education program to children. Students from 9th grade were eligible for participation from the school. The researcher visited each class and explained about the study and an open invitation had been extended to participate in the study. A notice also had been put on the notice board inviting students to participate in the study. A total of 50 students enrolled for the 
study. The study took place in four batches, each consisting of 15 to 18 school children. The training program was conducted for 3 days. Notes on the training sessions were made based on the observation. Each session was instantly assessed by taking feedback from the students about their perception of the quality, subject matter and its importance, time period of education sessions, and recommendation for improvements. Post-assessments were done after a month post-intervention. For ethical reasons, the investigator along with the co-investigators went back to the schools to carry out a half a day workshops for teachers and students of the selected schools. The intervention video was shown. Intervention manuals so created were handed over to the teachers for future reference.

\section{Tool for Data Collection}

Evaluation tool for KAP was created by conducting individual interviews with the children on knowledge, attitude, beliefs, and practices based on epilepsy using an interview guide. It was also based on statements from experienced clinicians on epilepsy awareness and review of literature. The framed instrument was then forwarded to subject experts for face validity. On their recommendations, the tool was modified a bit for the study. The researchers finalized the tool with a case demonstration of child having an episode of seizure to aid understating of seizures better with the developed KAP tool. The students filled the questionnaire and returned to investigator.

Table 1 Topics covered in the manual of epilepsy

\begin{tabular}{|l|l|}
\hline SI. No & Topics \\
\hline 1 & Introduction to epilepsy \\
\hline 2 & $\begin{array}{l}\text { How to tell the difference between one type of } \\
\text { seizure and another }\end{array}$ \\
\hline 3 & What can trigger a seizure \\
\hline 4 & Do I need to call an ambulance \\
\hline 5 & How to respond to a seizure \\
\hline 6 & Are there side effects with antiepileptic drugs \\
\hline 7 & Effects on learning \\
\hline 8 & How teachers can help-video show \\
\hline 9 & Epilepsy checklist at a glance \\
\hline
\end{tabular}

\section{Intervention Package}

An evaluation of the usually prescribed school course books was made to find out subject matter related to epilepsy. But, none of the reading material had any substance to up-skill the educators and school children about the disorder. An intervention module was framed by the researchers on the basis of the precedent assessment, targets, and recommendations of health experts. The intervention module had matter covering topics on epilepsy, its awareness based on the attitude and knowledge of the students, false beliefs related to the disorder, first aid that can be provided, as well as the practices related to epilepsy and what students can do in school. The intervention module also included Information Education Communication (IEC) material that was framed by the researchers to provide a comprehensive health education program. A video of 12 minutes was prepared on first aid that can be provided to a person with epilepsy by the researchers after suitable approval of script. This particular video was shot in the premises of a school, not selected for providing intervention. The video revolved around the plot of few school-going kids playing cricket in school. While playing, one of the kids having epilepsy had an attack of seizure. The video showed how a teacher came to rescue and provided first aid to the child. Additionally, posters aiming to create an awareness about the disorder thereby clearing the false beliefs were made by the researchers. Moreover, group activities and role plays were prepared as a part of the module. The developed intervention program was given to the experts from the field of health education and neurology for face and content validation. The research study additionally made efforts in including education on epilepsy in the regular syllabus for school children by educators. The manual was a comprehensive guide that covered the following topics ( - Table 1 ):

The same manual was used to train the teachers in TOT and the trainer also used while training children.

\section{Statistics}

The obtained data was analyzed using IBM SPSS version 20 (Armonk, New York, United States).

\section{Results}

- Table 2 shows the total sample size of the research study. Out of the 39 government teachers who were trained,

Table 2 Total sample of the study

\begin{tabular}{|c|c|c|c|c|c|}
\hline Category & Group & \multicolumn{2}{|c|}{ Number of participants } & Educational qualification & Total \\
\hline \multirow[t]{2}{*}{ Teachers } & \multirow[t]{2}{*}{ Trainer training to teachers } & \multicolumn{2}{|l|}{10} & PUC passed (12th grade) & \multirow[t]{2}{*}{39} \\
\hline & & \multicolumn{2}{|l|}{29} & Graduates & \\
\hline \multirow[t]{3}{*}{ Children } & \multirow{2}{*}{$\begin{array}{l}\text { Teachers imparted training to } \\
\text { children }\end{array}$} & Boys & Girls & \multirow[t]{2}{*}{ 9th grade } & \multirow[t]{2}{*}{50} \\
\hline & & 30 & 20 & & \\
\hline & $\begin{array}{l}\text { Researchers imparted training to } \\
\text { children }\end{array}$ & 35 & 15 & 9th grade & 50 \\
\hline \multicolumn{5}{|l|}{ Total $(n)$} & 139 \\
\hline
\end{tabular}

Abbreviation: PUC, pre-university college. 
around $25 \%$ has passed school, while the rest $75 \%$ were graduates. When it comes to the children, there were two categories, one in which the trained teachers imparted training to some children, the other in which the researchers imparted training to children. Both the categories had 50 children, all from 9 th grade. Number of boys were 30 and 35 , respectively, for both the groups when compared with girls that were 20 and 15 , respectively. A total of 65 boys and 35 girls participated in the study.

- Table 3 shows the General Linear Model of Knowledge. After performing the repeated measure of analysis of variance (ANOVA), Pillai's trace test was used to arrive at the inference based on Mauchly's test. It is inferred that knowledge is significantly different between pre- and posttest $(F=1134.875, p<0.001)$ as indicated by Pillai's trace test. Similarly, from the Pillai's test knowledge is also significantly different $(F=49.317, p<0.001)$ among the three groups. Therefore, we conclude that knowledge scores significantly differ between two time points and across three groups. Further, we can observe the changes in the line graph shown in -Fig. 1. It shows that in the preassessment all the three groups had similar level of knowledge (line 1), but after the intervention, it was increased significantly (line 2). Among all the groups, teachers imparted training group children had high level of knowledge.
- Table 4 shows the General Linear Model of Attitude. After performing the repeated measure of ANOVA, Pillai's trace test was used to arrive at the inference based on Mauchly's test. It is inferred that attitude is significantly different between pre- and posttest $(F=2429.909, p<0.001)$ as indicated by Pillai's trace test. Similarly, from the Pillai's test attitude is also significantly different ( $F=125.304$, $p<0.001$ ) among the three groups. Therefore, we conclude that attitude scores significantly differ between two time points and across three groups. Further, we can observe the changes in the line graph shown in - Fig. 2. It shows that in the preassessment, all the three groups had similar level of attitude (line 1), but after the intervention, it was increased significantly (line 2). Among all the groups, teachers imparted training group children had high level of attitude.

- Table 4 shows the general linear model of attitude. After performing the repeated measure of ANOVA, Pillai's trace test was used to arrive at the inference based on Mauchly's test. It is inferred that practice is significantly different between pre- and posttest $(F=2205.122, p<0.001$ ) as indicated by Pillai's trace test. Similarly, from the Pillai's test, practice is also significantly different $(F=178.697, p<0.001)$ among the three groups. Therefore, we conclude that practice scores significantly differ between two time points and across three groups. Further, we can observe the changes in the line graph shown in - Fig. $\mathbf{3}$.

Table 3 General linear model for knowledge

\begin{tabular}{|l|l|l|l|l|l|}
\hline Group & $\boldsymbol{n}$ & \multicolumn{2}{l|}{ Pretest } & \multicolumn{2}{l|}{ Posttest } \\
\cline { 3 - 6 } & & Mean & SD & Mean & SD \\
\hline Researchers imparted training to children & 50 & 36.58 & 3.44 & 46.66 & 5.32 \\
\hline Trainer training to teachers (TOT) & 39 & 37.51 & 3.42 & 50.74 & 3.74 \\
\hline Teachers imparted training to children & 50 & 34.22 & 2.25 & 54.06 & 3.35 \\
\hline Total & 139 & 35.99 & 3.34 & 50.47 & 5.28 \\
\hline
\end{tabular}

Abbreviation: SD, standard deviation.

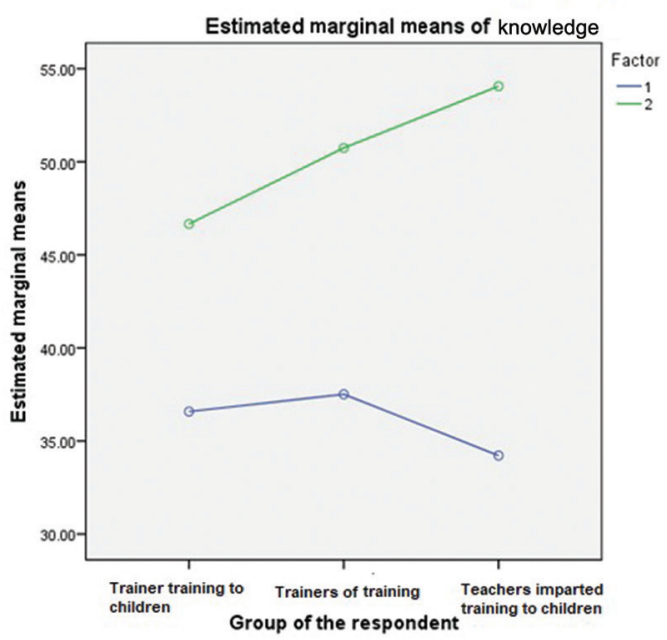

Fig. 1 Graphical representation of estimated marginal means of knowledge of different categories.

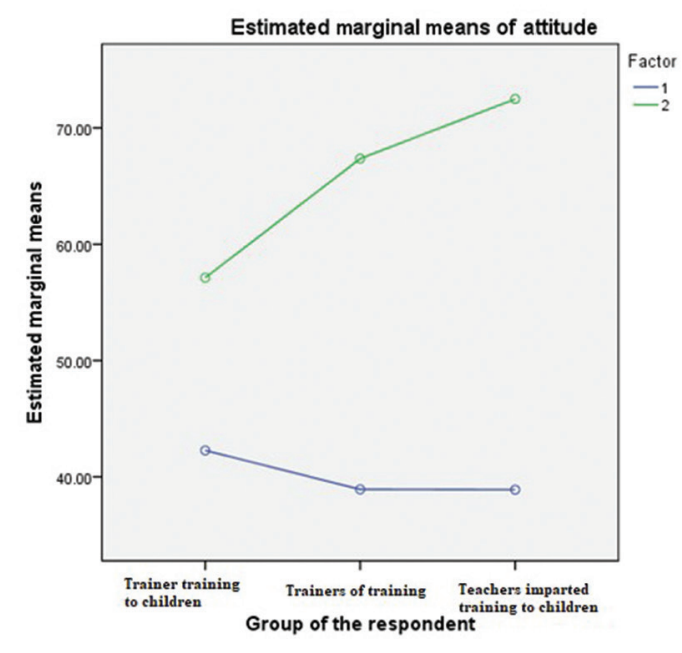

Fig. 2 Graphical representation of estimated marginal means of attitude of different categories. 
It shows that in the preassessment, all the three groups had similar level of practice (line 1 ), but after the intervention, it was increased significantly (line 2). Among all the groups, teachers imparted training group children had high level of practice.

\section{Discussion}

The present study compared the efficacy of the intervention of a health education program among three groups in school, that is, researchers imparted training to children, TOT, and teachers imparted training to children. The studies show that epilepsy is a common disorder and it affects large number of people around the globe. ${ }^{3}$ In India, it is the second leading public health problem due to its associated stigmatization that leads to social isolation and psychological effects which are well documented. Not only public but even teachers are not free from stigmatization and cultural barriers. Under this condition, children with epilepsy are more vulnerable for stigmatization, social isolation, lack of support, and psychological and emotional problems. ${ }^{1,3}$ Hence, there is a need to study the efficacy of the training programs on epilepsy. Knowledge is directly related to attitude and both are related to practices people do on epilepsy. The present study assessed the textbooks of the school and found that no textbooks had subject matter on epilepsy to impart knowledge to the teachers and school children. Studies report that in developing countries and in India, textbooks are not having the content of the epilepsy.,13

In the first level, TOT workshop was conducted on KAP. In the baseline, teachers had limited knowledge and had negative attitude. They reported to have faulty practices and beliefs, such as "Epilepsy is not curable and due to past sin a person would suffer from this ailment." After the intervention, 1-month later assessment shows that teachers' awareness knowledge has increased significantly and attitude and practices also changed significantly. During the follow-up, one teacher reported that "one student had seizure in my class and I was confident to handle the situation. After he regained the memory, I enquired about his medication complains and found that he was irregular on medicines. After this, I called his parents and counselled them about the need of regular medicines and follow-up with the treating doctor."

In the similar way, the same modules were introduced with the children by the trainer and some trained teachers. It shows that there is a difference between pre- and post-assessment in all three groups and also among the groups on KAP. After the intervention, KAP has changed significantly. Between training imparted by the researcher and teachers to children shows that teachers imparted

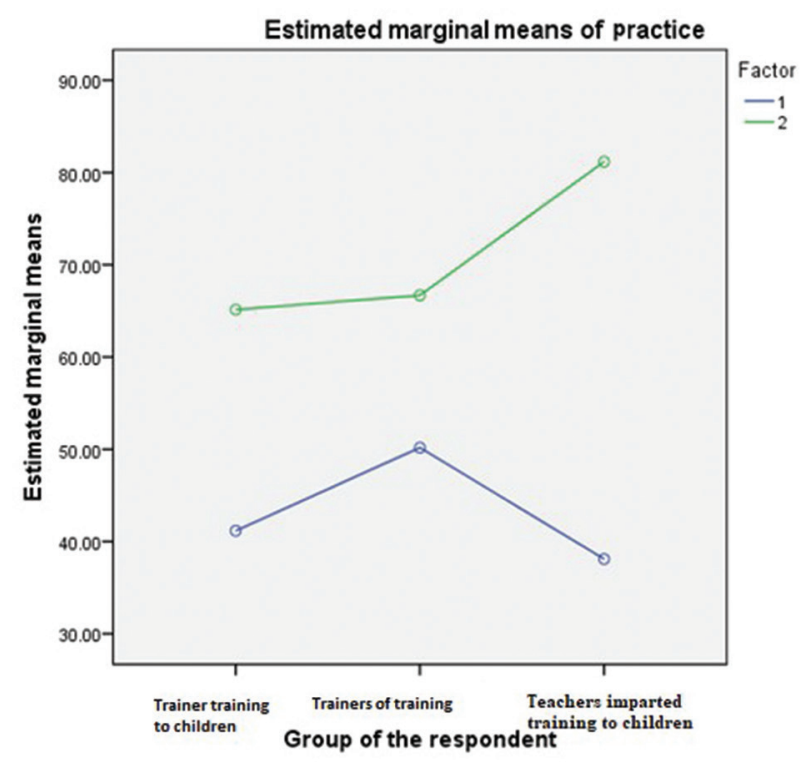

Fig. 3 Graphical representation of estimated marginal means of practice of different categories.

Table 4 General linear model for attitude

\begin{tabular}{|c|c|c|c|c|c|}
\hline \multirow[t]{2}{*}{ Group } & \multirow[t]{2}{*}{$n$} & \multicolumn{2}{|c|}{ Pretest } & \multicolumn{2}{|c|}{ Posttest } \\
\hline & & Mean & SD & Mean & SD \\
\hline Researchers imparted training to children & 50 & 42.28 & 5.05 & 57.12 & 5.26 \\
\hline Trainer training to teachers (TOT) & 39 & 38.92 & 6.60 & 67.35 & 3.21 \\
\hline Teachers imparted training to children & 50 & 38.90 & 3.09 & 72.48 & 2.59 \\
\hline Total & 139 & 40.12 & 5.20 & 65.52 & 7.69 \\
\hline
\end{tabular}

Abbreviation: SD, standard deviation.

Table 5 General linear model for practice

\begin{tabular}{|l|l|l|l|l|l|}
\hline Group & $\boldsymbol{n}$ & \multicolumn{2}{l|}{ Pretest } & \multicolumn{2}{l|}{ Posttest } \\
\cline { 3 - 7 } & & Mean & SD & Mean & SD \\
\hline Researchers imparted training to children & 50 & 41.16 & 4.35 & 65.14 & 5.95 \\
\hline Trainer training to teachers (TOT) & 39 & 50.18 & 6.57 & 66.69 & 12.47 \\
\hline Teachers imparted training to children & 50 & 38.10 & 3.56 & 81.18 & 2.22 \\
\hline Total & 139 & 42.59 & 6.89 & 71.34 & 10.59 \\
\hline
\end{tabular}

Abbreviation: SD, standard deviation. 
training showed more KAP than trainer. This demonstrates that teachers training is more effective than trainer. Hence, training the teachers and imparting to children are more important. Studies show that during the young age pupil listen and follow teachers' instructions than others. Hence, training teachers and including in the text would bring good results and make long-lasting effects on pupil. Including in the textbooks would bring down the stigmatization, encourage socialization, decrease the cultural barriers, self-esteem, etc.

\section{Conclusion}

The review shows that there are not more studies conducted on Impact of a Health Education Program for Epilepsy Awareness among school teachers and children. This is a first study conducted to assess the impact of teachers imparted training to children. Literature shows that school curriculum does not have epilepsy related lessons in their syllabus and thus children and teachers lack knowledge on epilepsy. The present study demonstrates that through imparting the training from teachers to pupil in creating awareness is more effective than a trainer. Acceptance of teachers training is more effective. Hence, including the epilepsy awareness in curriculum or in teachers training syllabus would help to prevent unacceptable practices and change the attitude of the pupil as well as teacher.

\section{Conflict of Interest}

None declared.

\section{References}

1 Kabir M, Iliyasu Z, Abubakar IS, Kabir ZS, Farinyaro AU. Knowledge, attitude and beliefs about epilepsy among adults in a northern Nigerian urban community. Ann Afr Med 2005;4(3):107-112

2 Yoo JK, Jung KY, Park KW, et al. Familiarity with, understanding of, and attitudes toward epilepsy among people with epilepsy and healthy controls in South Korea. Epilepsy Behav 2009;16(2):260-267
3 Yemadje LP, Houinato D, Quet F, Druet-Cabanac M, Preux PM. Understanding the differences in prevalence of epilepsy in tropical regions. Epilepsia 2011;52(8):1376-1381

4 Lahoti N. [2016]. 11 Troublesome Myths about Epilepsy. Retrieved from: https://www.practo.com/healthfeed/ 11-troublesome-myths-about-epilepsy-12703/post

5 Austin JK, Shafer PO, Deering JB. Epilepsy familiarity, knowledge, and perceptions of stigma: report from a survey of adolescents in the general population. Epilepsy Behav 2002;3(4):368-375

6 Owolabi LF, Shehu NM, Owolabi SD. Epilepsy and education in developing countries: a survey of school teachers' knowledge about epilepsy and their attitude towards students with epilepsy in Northwestern Nigeria. Pan Afr Med J 2014;18:255

7 Kolar Sridara Murthy M, Govindappa L, Sinha S. Outcome of a school-based health education program for epilepsy awareness among schoolchildren. Epilepsy Behav 2016;57(Pt A):77-81

8 Krishnaiah B, Alwar SP, Ranganathan LN. Knowledge, attitude, and practice of people toward epilepsy in a South Indian village. J Neurosci Rural Pract 2016;7(3):374-380

9 Fernandes PT, Cabral P, Araújo U, Noronha ALA, Li LM. Kids' perception about epilepsy. Epilepsy Behav 2005;6(4):601-603

10 Pandian JD, Santosh D, Kumar TS, Sarma PS, Radhakrishnan K. High school students' knowledge, attitude, and practice with respect to epilepsy in Kerala, southern India. Epilepsy Behav 2006;9(3):492-497

11 Baker GA, Jacoby A, Buck D, Stalgis C, Monnet D, Monnet D. Quality of life of people with epilepsy: a European study. Epilepsia 1997;38(3):353-362

12 Gourie-Devi M, Satishchandra P, Gururaj G. Epilepsy control program in India: a district model. Epilepsia 2003;44(Suppl 1):58-62

13 Goel S, Singh N, Lal V, Singh A. Evaluating the impact of comprehensive epilepsy education programme for school teachers in Chandigarh city, India. Seizure 2014;23(1):41-46

14 Al-Harbi AF, Alsaid LA, Parameaswari PJ. Primary school female teachers' knowledge, attitude, and practice toward students with epilepsy in Riyadh, Saudi Arabia. J Family Med Prim Care 2018;7(2):331-336 